\title{
Magnesium pemoline: Effects on avoidance conditioning mediated by anticipatory responses
}

JERRY COLLINS AND M. R. D'AMATO, DEPARTMENT OF PSYCHOLOGY, RUTGERS UNIVERSITY, New Brunswick, N.J. 08903

Magnesium pemoline facilitated acquisition of an avoidance response in moderate-sized rats but had little effect on larger animals. The drug had parallel effects on conditioned ("anticipatory") responses in control groups that did not have the benefit of an avoidance contingency. The results support the view that where magnesium pemoline enhances avoidance acquisition it does so by augmenting anticipatory responding.

Recently there has been a flurry of studies investigating the effects of magnesium pemoline on avoidance acquisition, the primary reason being the reported effect of this drug on the systems that synthesize brain nucleic acid (Glasky \& Simon, 1966). There now is a consensus that magnesium pemoline often facilitates avoidance acquisition in a variety of apparatuses (e.g., Beach \& Kimble, 1967; Filby, Szara, \& Salzman, 1967; Frey \& Polidora, 1967; Plotnikoff, 1966). However, the mechanism through which this effect is mediated is not clear. Some feel that, rather than affecting learning processes, the drug increases general "activity level" or interferes with the "freezing" behavior which frequently accompanies application of aversive stimuli. Existing data (Beach \& Kimble, 1967; Boitano \& Boitano, 1967) show clearly that magnesium pemoline does lead to increases in general activity level and responsivity to a buzzer stimulus-which has frequently served as the conditioned stimulus in avoidance studies.

While these latter results are suggestive they do not specify the means through which increased activity or responsivity acts to facilitate avoidance acquisition. We have recently advanced an analysis of avoidance acquisition which may be useful in this regard (D'Amato, Fazzaro, \& Etkin, 1968). According to this view initial conditioned responses (CRs) in avoidance conditioning are generated by factors other than the avoidance contingency, as testified by the fact that substantial numbers of CRs occur even if avoidance of the unconditioned stimulus (UCS) is impossible (e.g., D'Amato et al, 1968). The occurrence of such CRs ("anticipatory" responses) in sufficient numbers puts the $S$ in a position to discriminate the avoidance contingency, if one is operating.

Thus a variable that facilitates avoidance acquisition may do so simply because it enhances the level of anticipatory responding. As an illustration, relatively strong shock has been repeatedly shown to inhibit avoidance acquisition (D'Amato \& Fazzaro, 1966; Moyer \& Korn, 1964). Recent research in our laboratory has demonstrated that strong shock profoundly inhibits anticipatory responding, the magnitude of the effect being sufficient to account for the influence of shock intensity on avoidance acquisition (D'Amato, Etkin, \& Fazzaro, in press).

In view of the effects of magnesium pemoline on activity level, it is likely that this drug facilitates avoidance acquisition for the same reason. We should stress, however, that the mere demonstration that an agent increases general activity level or related behaviors by no means assures that this is the mechanism through which enhancement of avoidance conditioning occurs. Whether the latter implication follows depends entirely on the relationship that exists between the instrumental (avoidance) response employed and the behavior measured under "activity level." The aim of the following experiments was to close the inferential gap by assessing the degree of correspondence in the effects of magnesium pemoline on avoidance acquisition and anticipatory responding.

\section{EXPERIMENT 1}

Method. In the first experiment 24 female and 24 male albino rats (mean weight: 250 and $411 \mathrm{~g}$, respectively), of Wistar and Sprague-Dawley lineage, were trained on a discriminated avoidance task in a shuttle box apparatus. The latter consisted of two compartments separated by a centrally placed door. The S's task was, upon presentation of the conditioned stimulus (comprised of an illumination increase and a white noise of $80 \mathrm{~dB}$ ), to enter the opposite compartment before the onset of shock (.4 mA, delivered by a constant current, grid-scrambling, source). The interval separating onset of the conditioned stimulus from onset of shock, the CS-UCS interval, was $\dot{5}$ sec. In the "avoidance" groups responding prior to the termination of the CS-UCS interval (avoidance responses) prevented the delivery of shock, and the $S$ was safe until the next trial. In the "nonavoidance" groups, however, such responses had no effect whatever upon the presentation of the UCS. At the end of the CS-UCS interval, shock was applied in the compartment where the $S$ was located and remained there until the $S$ escaped into the other compartment. Because CRs do not serve to avoid shock in the nonavoidance groups, they are referred to as anticipatory, rather than avoidance, responses. Sixty trials, separated by an average intertrial interval of $45 \mathrm{sec}$, were given in a single experimental session.

A third of the Ss were injected intraperitoneally with $10 \mathrm{mg} / \mathrm{kg}$ magnesium pemoline (suspended in .5\% methocel solution), a third with $20 \mathrm{mg} / \mathrm{kg}$ magnesium pemoline, and the remaining third, the placebo controls, received an injection of the methocel alone in equal volume. All injections were administered approximately $1 \mathrm{~h}$ prior to the beginning of avoidance training (Brink \& Stein, 1967). The experiment, then, comprised a factorial design

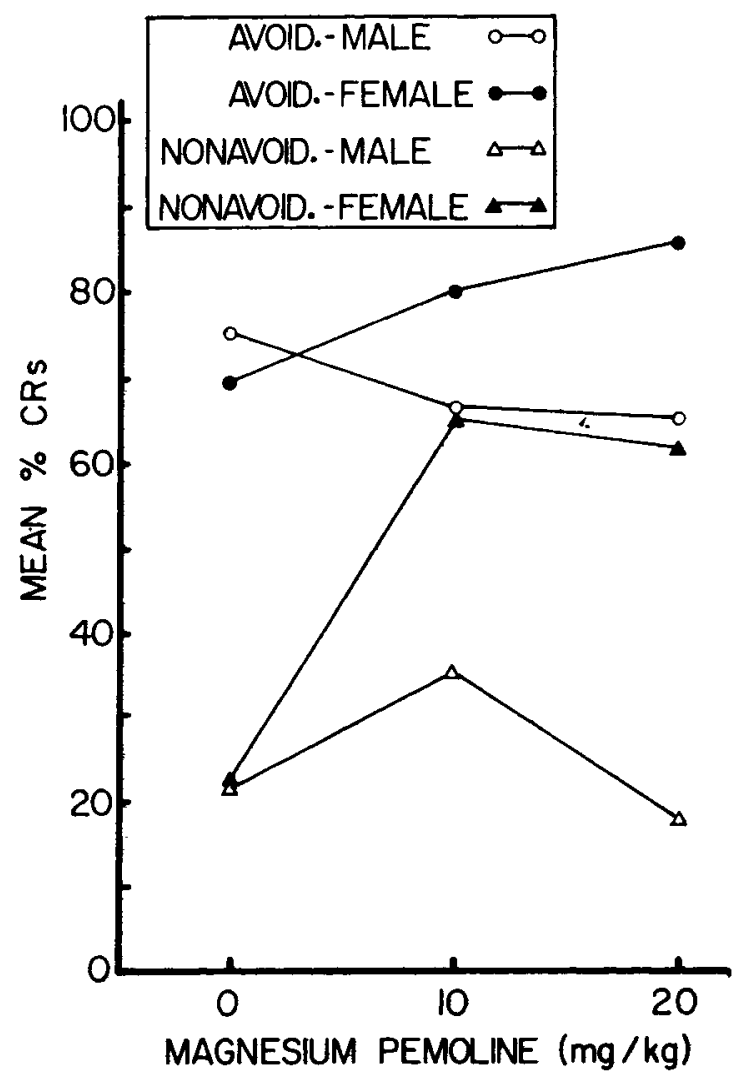

Fig. 1. Percentage of conditioned responses in the various groups of Experiment 1 as a function of injected dosage of magnesium pemoline. In the nonavoidance groups conditioned responses did not lead to avoidance of shock. 


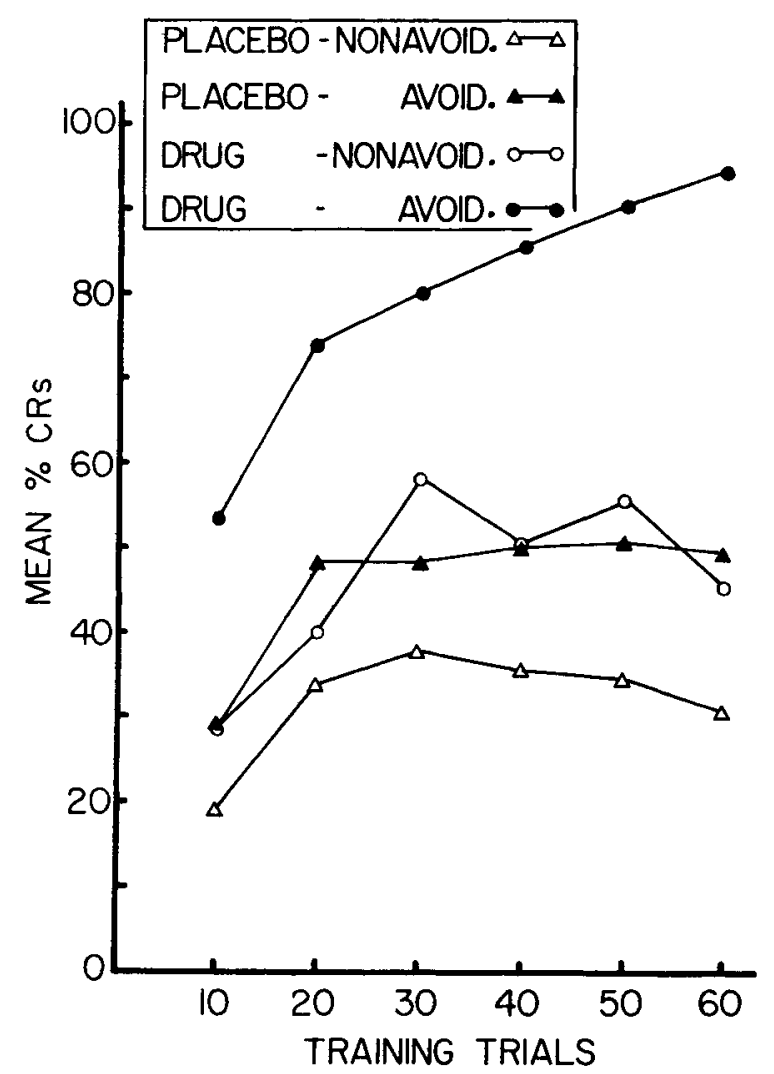

Fig. 2. Percentage conditioned responses in placebo and magnesium pemoline $(10 \mathrm{mg} / \mathrm{kg})$ injected groups over the 60 avoidance acquisition trials of Experiment 2. Conditioned responses did not serve to avoid shock in the nonavoidance groups.

over the three variables of sex, avoidance contingency (present or absent), and drug level $(0,10$, or $20 \mathrm{mg} / \mathrm{kg})$.

Results and Discussion. The results, in terms of the percentage CRs over the 60 training trials, are shown in Fig. 1. Note that magnesium pemoline enhances avoidance responding in the female Ss and it has a similar, though more pronounced, effect on anticipatory responses in the female nonavoidance groups. On the other hand, the drug has only a slight inhibiting effect in the male avoidance groups, and correspondingly there is no evidence of facilitation of anticipatory responding in the parallel male nonavoidance groups. The different effect which magnesium pemoline had in males and females was revealed in a significant Drug by Sex interaction $(p<.01)$. (The drug by sex by avoidance contingency interaction was far from significant, $F=.20$.) A similar interaction $(p<.01)$ was obtained from data based on response latencies. For each $S$ the reciprocal latency of each $C R$ was calculated and the mean of these values entered into an analysis of variance. While the females showed shorter latencies with increasing drug level, the males produced the opposite trend.

We interpreted the different effect that magnesium pemoline had on males and females to be a result of the difference in the size of the animals rather than in their sex. The same shock level was employed with both sexes and the substantially heavier males tended to react to the rather mild shock with a response of "digging in." Possibly the drug enhanced this tendency by rendering an already marginal aversive stimulus less noxious.

\section{EXPERIMENT 2}

A second study, similar in all details to the first, was conducted employing 32 male Sprague-Dawley rats (mean weight $281 \mathrm{~g}$ ).
There were four experimental groups generated by the avoidance contingency and drug ( 0 or $10 \mathrm{mg} / \mathrm{kg}$ ) variables.

Results. The acquisition data are shown in blocks of 10 trials in Fig. 2. It is clear that, as with the females of the first experiment, magnesium pemoline augmented both avoidance and anticipatory responses. Note that both effects are detectable in the first block of 10 trials, and observe that throughout training the drugnonavoidance group performed as well as the placebo-avoidance animals. The drug effect was significant $(p<.025)$, while the interaction between drug and contingency was not $(\mathrm{F}=1.40)$.

Discussion. The pattern of results obtained in the two experiments supports our conjecture that where magnesium pemoline facilitates avoidance conditioning it does so through the mechanism of anticipatory responding. Possibly anticipatory responses are increased by magnesium pemoline in some situations by virtue of the drug's effect on general activity level, but as already pointed out there is not a necessary relationship between the two. Although relatively strong shock was found to suppress anticipatory responses in a bar-press avoidance task (D'Amato et al, in press) it did not result in fewer intertrial responses, which presumably are related to general activity level. It would seem desirable, therefore, to include where possible nonavoidance control groups to assess the effect of magnesium pemoline on anticipatory responses rather than risk inferences based on measures of activity level or related behavior.

As one of us has recently pointed out (D'Amato, 1967), control groups in which the avoidance contingency is deleted would seem to be generally desirable where one is assessing the effects of an independent variable on avoidance acquisition. $A$ variable which enhances avoidance acquisition while having little effect on anticipatory responses probably acts through a different mechanism than one which has comparable effects on both of these behaviors.

\section{REFERENCES}

BEACH, G., \& KIMBLE, D. P. Activity and responsivity in rats after magnesium pemoline injections. Science, 1967, 155, 698-701.

BOITANO, J. J., \& BOITANO, J. C. Magnesium pemoline: Enhancement of spontaneous motor activity. Psychon. Sci. 1967, 9, 295-296.

BRINK, J. J., \& STEIN, D. G. Pemoline levels in brain: Enhancement by dimethyl sulfoxide. Science, 1967, 158, 1479-1480.

D'AMATO, M. R. Role of anticipatory responses in avoidance conditioning: An important control. Psychon. Sci, 1967, 8, 191-192.

D'AMATO, M. R., ETKIN, M., \& FAZZARO, J. Effects of shock type and intensity on anticipatory ("avoidance") responses. J. comp. physiol. Psychol, in press.

D'AMATO, M. R., \& FAZZARO, J. Discriminated lever-press avoidance learning as a function of type and intensity of shock. J. comp. physiol. Psychol, 1966, 61, 313-315.

D'AMATO, M. R., FAZZARO, J., \& ETKIN, M. Anticipatory responding and avoidance discrimination as factors in avoidance conditioning. $J$. exp. Psychol., 1968, 77, 41-47.

FILBY, Y., SZARA, S., \& SALZMAN, B. Magnesium pemoline: Effects on acquisition and retention of discriminated avoidance behavior. Psychon. Sci, 1967, 9, 131-132.

FREY, P. W., \& POLIDORA, V. J. Magnesium pemoline: Effects on avoidance conditioning in rats. Science, 1967, 155, 1281-1282.

GLASKY, A. J., \& SIMON, L. N. Magnesium pemoline: Enhancement of brain RNA polymerases. Science, 1966, 151, 702-703.

MOYER, J. E., \& KORN, J. H. Effects of UCS intensity on the acquisition and extinction of an avoidance response. J. exp. Psychol, 1964, 67, 352-359.

PLOTNIKOFF, N. Magnesium pemoline: Enhancement of learning and memory of a conditioned avoidance response. Science, 1966, 151, 703-704.

\section{NOTE}

1. The magnesium pemoline was kindly supplied by Abbott Laboratories, North Chicago, Illinois. The research was supported by NSF Grant GB-4011 to MRD. 